\title{
Review could speed up German grants
}

[MUNICH] Germany's main funding body for university research, the Deutsche Forschungsgemeinschaft (DFG), is undergoing its first external evaluation. The result could be wide-ranging reforms - including perhaps the speeding up of the peer-review process - next year, the fiftieth anniversary of the DFG's re-establishment after the Second World War.

The idea of an extensive external evaluation was proposed by the DFG two years ago. A group of ten international experts was appointed by the Bund-Länder-Kommission, which coordinates federal and state governments' research policy. The group is headed by Richard Brooke, chief executive of the UK Engineering and Physical Sciences Research Council, and held its first discussions in Bonn last month.

The evaluation will focus particularly on the DFG's grants system. Ernst-Ludwig Winnacker, the new DFG president, is concerned that many grants last for too short a period, and that the reviewing procedure takes too long - and is out of line with European norms. In contrast to the United Kingdom and the United States, where major grantgiving bodies appoint their own referees, the scientific community elects the DFG's 500 or so referees every four years. Winnacker asks whether "democracy [is] the best way forward to scientific excellence".

Most German researchers appear reluctant to abandon the democratic culture of the review system. A survey last year of 1,200 recent DFG grant applicants - plus a further 200 academics who had not applied for grants recently - found 80 per cent in favour of the election of referees.

But a substantial criticism raised by the survey was the length of time it takes the DFG to decide about grant applications - an average of about six-and-a-half months. Many researchers complain that this causes unnecessary uncertainty.

Working with the evaluation committee, the DFG is investigating ways of halving this time. Its somewhat random method for choosing referees for particular applications is seen as a significant factor in the delays, as those selected in this way are frequently unavailable. The DFG wants to guarantee the availability of a certain referee in future, using a computerized information system.

The agency also wants the evaluation committee to consider its at present modest programme for young scientists. This is a subject close to the heart of Winnacker, who believes that young scientists need to be given responsibility for running their own research groups much earlier than at present, to encourage them to remain in Germany (see Nature 388, 507; 1997).

Last year, the DFG created a programme for young life scientists, allowing them to apply not only for research grants for a fiveyear period - instead of the normal two or three years - but also for their own salaries, which it does not normally allow. But only three such grants are available each year.

DFG officials are hoping that a recommendation from the evaluation group could help to expand the programme. Budgetary pressure has made it difficult for the organization to agree internally on expansion because even now only a low proportion of approved applications in other programmes can be funded.

But the DFG remains cautious about the effectiveness of the evaluation committee's report, due next year. "You can never predict if, and when, politicians are willing to match action to words," says Christoph Schneider, director for scientific and international affairs. Further inspections by and meetings of the evaluation group are planned for July and December.

QuirinSchiermeier

\section{Russian church and scientists lay revolutionary quarrels to rest}

[MOsCow] Prominent Russian scientists and religious leaders have met to proclaim their common interests for the first time since before the 1917 Revolution. Unlike 1917, when religion was branded the "opium of the people", the scientists declared little conflict with religious thought, while their religious counterparts expressed concern about the lack of funding for science.

Both were attending a meeting called 'Faith and Knowledge: Science and Technology at the Frontier of Two Centuries', in Moscow last week. The Worldwide Russian National Council meeting was organized under the auspices of the Russian Orthodox Church and the Russian Academy of Sciences - a combination that would have been unthinkable only ten years ago.

The Russian Orthodox Church's patriarch for Moscow and the whole of Russia, Alexsiy the Second, said: "Russia is the great scientific state, but the present economic crisis has damaged its scientific and technological potential, which means that in the coming century the country will face difficult obstacles."

He added: "Russia's fate is now in the hands of scientific intelligentsia, and whether or not these people are ready to mobilize their abilities and strengths to

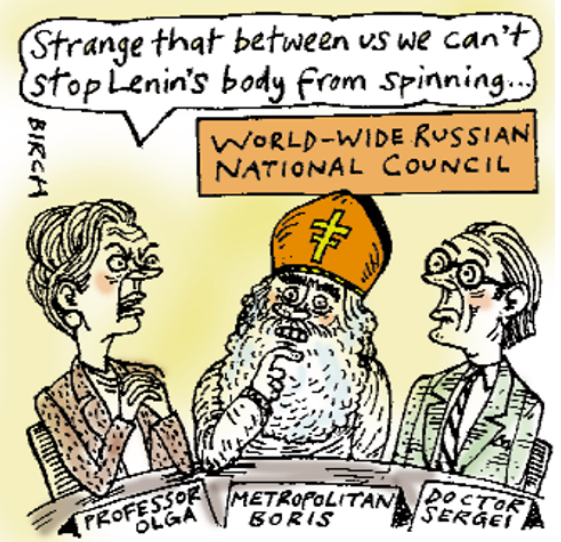

serve Russia could not but be our church's concern."

The meeting represented the first time for at least $\mathbf{8 0}$ years that scientists and clergymen have met in Russia. During the Soviet era, religion was officially discouraged, and one of the major tasks of the Academy of Sciences was to promote anti-religious propaganda.

The situation today is very different. "Science is not in conflict with religion, and religion is also based on rationality, it's a kind of rationality," said Yuri Osipov, the president of the Russian Academy of Sciences. "A process of convergence is now taking place between science and religion; they interact in building the humanoriented values of our culture."

Other speakers supported Osipov by pointing out that more than 40 per cent of scientists now openly call themselves believers - formerly all were considered to be atheists - whereas many clergymen hold scientific degrees from universities, another unprecedented step. Some scientists even compared the act of scientific discovery to a religious experience.

Vladimir Fortov, vice-president of the Academy of Sciences and until this week minister of science and technologies, said that science and religion have much in common; only their methods of understanding the natural world are different. The Big Bang theory, for example, is close to the theological view on the origin of the Universe, he said.

But the Russian Orthodox Church is not entirely enthusiastic about modern science. It strongly opposes any research on cloning not only humans but animals in general, and is suspicious about many other fields of science. "Nuclear weapons, artificial intelligence, information systems and genetic engineering, all contain a 'phantom' of enormous danger," said the Metropolitan Bishop Kirill.

Carl Levitin 